\title{
Differential expression of microRNAs in porcine parvovirus infected porcine cell line
}

\author{
Xinqiong $\mathrm{Li}^{1 \dagger}$, Ling Zhu ${ }^{1,2+}{ }^{\text {, Xiao Liu }}{ }^{1}$, Xiangang Sun ${ }^{1}$, Yuanchen Zhou', Qiaoli Lang ${ }^{1}$, Ping Li', Yuhan Cai ${ }^{1}$,
} Xiaogai Qiao ${ }^{1}$ and Zhiwen $X u^{1,2^{*}}$

\begin{abstract}
Background: Porcine parvovirus (PPV), a member of the Parvoviridae family, causes great economic loss in the swine industry worldwide. MicroRNAs (miRNAs) are a class of non-protein-coding genes that play many diverse and complex roles in viral infections.

Finding: Aiming to determine the impact of PPV infections on the cellular miRNAome, we used high-throughput sequencing to sequence two miRNA libraries prepared from porcine kidney 15 (PK-15) cells under normal conditions and during PPV infection. There was differential miRNA expression between the uninfected and infected cells: 65 miRNAs were upregulated and 128 miRNAs were downregulated. We detected the expression of miR-10b, miR-20a, miR-19b, miR-181a, miR-146b, miR-18a, and other previously identified immune-related miRNAs. Gene Ontology analysis and KEGG function annotations of the host target genes suggested that the miRNAs are involved in complex cellular pathways, including cellular metabolic processes, immune system processes, and gene expression.

Conclusions: These data suggest that a large group of miRNAs is expressed in PK-15 cells and that some miRNAs were altered in PPV-infected PK-15 cells. A number of microRNAs play an important role in regulating immune-related gene expression. Our findings should help with the development of new control strategies to prevent or treat PPV infections in swine.
\end{abstract}

\section{Background}

Porcine parvovirus (PPV) is a major cause of reproductive failure in swine (Sus scrofa, ssc), where infection is characterized by early embryonic death, stillbirths, fetal death, and delayed return to estrus [1]. Additionally, PPV is associated with porcine postweaning multisystemic wasting syndrome (PMWS) and diarrhea, skin disease, and arthritis in swine $[1,2]$. Even though inactivated and attenuated vaccines are widely used, the PPV-associated diseases nevertheless cause serious economic losses to the swine industry worldwide [3]. As virus replication is highly dependent on the host cell, cellular microRNA (miRNA) modification of the complex cellular regulatory networks can greatly influence viral reproduction and pathogenesis. Therefore, determining the consequences of PPV infections on cellular gene regulatory networks is urgent.

\footnotetext{
*Correspondence: abtcxzw@126.com

${ }^{\dagger}$ Equal contributors

'Animal Biotechnology Center, College of Veterinary Medicine, Sichuan Agricultural University, Wenjiang, Chengdu, China

${ }^{2}$ Key Laboratory of Animal Disease and Human Health, College of Veterinary Medicine, Sichuan Agricultural University, Wenjiang, Chengdu, China
}

miRNAs are involved in post-transcriptional regulation of gene expression in animals, plants, and some DNA viruses. miRNAs act as regulators, inhibiting the expression of specific mRNAs by recognizing partial complementary sites in a targeted mRNA, typically within the 3 ' untranslated region (3'UTR). miRNAs perform critical functions in diverse biological processes, including proliferation, apoptosis, and cell differentiation [4]. It has been well established that miRNAs play many complex roles during viral infection [5]. Therefore, an increasing number of researchers have focused on the relationship between viruses and miRNAs.

As far as we know, knowledge on the role of miRNAs in PPV infection is lacking. In this study, we detected the miRNAs expressed in porcine kidney 15 (PK-15) cells following PPV infection using high-throughput sequencing.

\section{Methods}

We used the PPV-SC-L strain, stored at the Key Laboratory of Animal Diseases and Human Health of Sichuan Province, China, in this study. PK-15 cell cultures that were $50 \%$ confluent were infected with PPV at 10 plaque- 
Table 1 RT-qPCR primers

\begin{tabular}{|c|c|c|}
\hline Gene & \multicolumn{2}{|l|}{ RT primer } \\
\hline U6 & \multicolumn{2}{|l|}{ 5'CGCTTCACGAATTTGCGTGTCAT3' } \\
\hline miR-RT Primer & \multicolumn{2}{|c|}{ 5'GTCGGTGTCGTGGAGTCGTTTGCAATTGCACTGGATTITाTाTाTाTाTाTाV3' } \\
\hline \multicolumn{3}{|l|}{$V=A, G, C$} \\
\hline Gene & Forward primer $\left(5^{\prime}-3^{\prime}\right)$ & Reversed primer $\left(5^{\prime}-3^{\prime}\right)$ \\
\hline ssc-miR-10b & TACCCTGTAGAACCGAATTTGT & GTCGGTGTCGTGGAGTCG \\
\hline ssc-miR-30a-5p & TGTAAACATCCTCGACTGGAAG & GTCGGTGTCGTGGAGTCG \\
\hline ssc-miR-16 & TAGCAGCACGTAAATATTGGC & GTCGGTGTCGTGGAGTCG \\
\hline ssc-miR-17-5p & CAAAGTGCTTACAGTGCAGGTAG & GTCGGTGTCGTGGAGTCG \\
\hline ssc-miR-192 & CTGACCTATGAATTGACA & GTCGGTGTCGTGGAGTCG \\
\hline ssc-miR-21 & TAGCTTATCAGACTGATGTTGA & GTCGGTGTCGTGGAGTCG \\
\hline ssc-miR-19b & TGTGCAAATCCATGCAAAAC & GTCGGTGTCGTGGAGTCG \\
\hline ssc-miR-18a & TAAGGTGCATCTAGTGCAGATA & GTCGGTGTCGTGGAGTCG \\
\hline ssc-miR-152 & TCAGTGCATGACAGAACTTGG & GTCGGTGTCGTGGAGTCG \\
\hline ssc-miR-novel-chr13_10861 & TTCAAGTAACCCAGGATAGGCT & GTCGGTGTCGTGGAGTCG \\
\hline U6 & TCGCTTTGGCAGCACCTAT & AATATGGAACGCTTCGCAAA \\
\hline
\end{tabular}

forming units (PFU) per cell. PK-15 cells inoculated with DMEM were maintained as uninfected control cells. Cells were harvested at $24 \mathrm{~h}$ post-infection [6]. The cultures for each group were performed in triplicate. The infected and uninfected cells were mixed separately and used for RNA extraction. Cell viability is not affected during timecourse of infection.
Total RNA from infected PK-15 cells and normal PK15 cells was extracted using TRIzol (Invitrogen) according to the manufacturer's instructions. RNA quality was assessed by formaldehyde/agarose gel electrophoresis and was quantified using a ND-1000 NanoDrop Spectrophotometer (Thermo Scientific, Wilmington, MA, USA). Approximately $20 \mu \mathrm{g}$ total RNA was subjected to
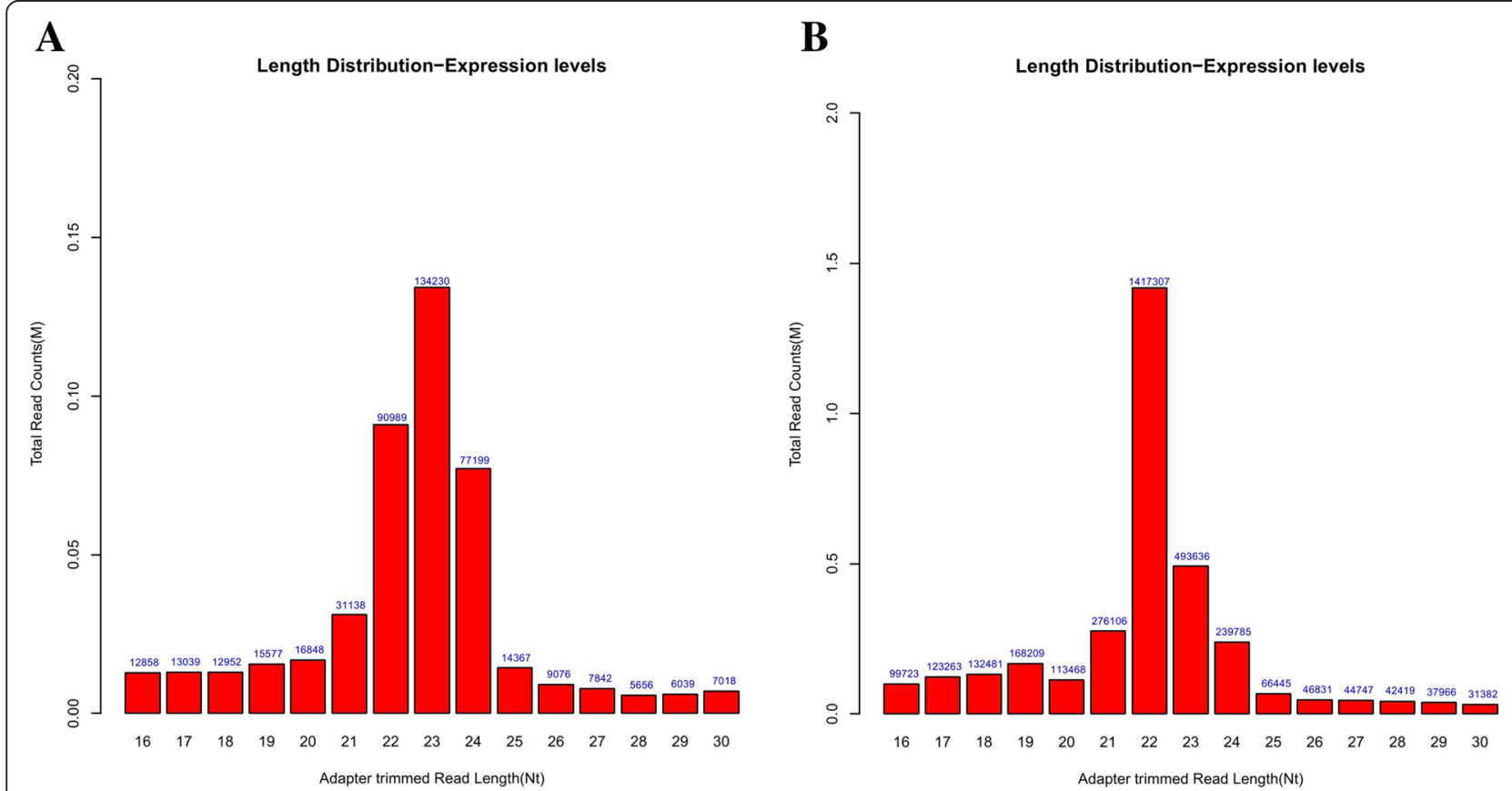

Fig. 1 Length distribution of miRNA reads from Solexa sequencing. a Adapter-trimmed reads in the infected library; b adapter-trimmed reads in the control library 
Table 2 Top 50 miRNAs significantly up- or downregulated in PK-15 cells in order of fold change (FC)

\begin{tabular}{|c|c|c|c|c|c|c|}
\hline \multirow[t]{2}{*}{ Annotation } & \multicolumn{2}{|c|}{ Normalized read counts } & \multirow[t]{2}{*}{ length } & \multirow[t]{2}{*}{ type } & \multirow[t]{2}{*}{ FC } & \multirow{2}{*}{$\begin{array}{l}\text { Number } \\
\text { of target } \\
\text { genes }\end{array}$} \\
\hline & infected & control & & & & \\
\hline ssc-miR-10b & 42,588 & 1162 & 22 & Up & 36.35 & 738 \\
\hline ssc-miR-192 & 3769 & 102 & 21 & Up & 33.74 & 718 \\
\hline ssc-miR-20a & 2432 & 116 & 22 & Up & 19.38 & 1490 \\
\hline ssc-miR-296-3p & 195 & 3 & 21 & Up & 15.77 & 1863 \\
\hline ssc-miR-novel-chr17-18987 & 195 & 3 & 19 & Up & 15.77 & 1864 \\
\hline ssc-miR-92b-3p & 2215 & 133 & 22 & Up & 15.56 & 1757 \\
\hline ssc-miR-30a-5p & 98,034 & 6320 & 22 & Up & 15.49 & 1147 \\
\hline ssc-miR-novel-chr12-7961 & 1886 & 191 & 22 & Up & 9.43 & 1357 \\
\hline ssc-miR-novel-chr14-13888 & 582 & 58 & 23 & Up & 8.71 & 1368 \\
\hline ssc-miR-34a & 358 & 37 & 22 & Up & 7.83 & 1663 \\
\hline ssc-miR-novel-chr16-17559 & 55 & 0 & 22 & Up & 6.5 & 1610 \\
\hline SSc-miR-novel-JH11865-1-42 & 55 & 0 & 23 & Up & 6.5 & 1727 \\
\hline ssc-miR-17-5p & 2868 & 438 & 23 & Up & 6.42 & 1443 \\
\hline ssc-miR-16 & 11,873 & 1891 & 22 & Up & 6.25 & 1763 \\
\hline ssc-miR-22-3p & 2267 & 365 & 22 & Up & 6.07 & 1487 \\
\hline ssc-miR-146b & 75 & 3 & 21 & Up & 6.07 & 1139 \\
\hline ssc-miR-155-5p & 426 & 62 & 22 & Up & 6.06 & 1146 \\
\hline ssc-miR-novel-chr2-20965 & 52 & 1 & 23 & Up & 5.64 & 1147 \\
\hline ssc-miR-novel-chrx-40705 & 758 & 147 & 22 & Up & 4.89 & 811 \\
\hline ssc-miR-221-3p & 758 & 147 & 22 & Up & 4.89 & 811 \\
\hline ssc-miR-301 & 114 & 17 & 23 & Up & 4.59 & 1509 \\
\hline ssc-miR-191 & 741 & 156 & 23 & Up & 4.52 & 695 \\
\hline ssc-miR-novel-chr6-31692 & 46 & 3 & 22 & Up & 4.30 & 2019 \\
\hline ssc-miR-181a & 637 & 147 & 24 & Up & 4.12 & 1221 \\
\hline ssc-miR-18a & 88 & 9541 & 22 & Down & 0.0102 & 995 \\
\hline ssc-miR-novel-chr9-37990 & 20 & 1752 & 23 & Down & 0.0170 & 1512 \\
\hline ssc-miR-novel-chr9-39041 & 20 & 1752 & 23 & Down & 0.0170 & 1512 \\
\hline ssc-miR-novel-chr6-30729 & 13 & 1317 & 22 & Down & 0.0173 & 1083 \\
\hline ssc-miR-424-5p & 33 & 2182 & 22 & Down & 0.0196 & 1817 \\
\hline ssc-miR-31 & 55 & 3118 & 22 & Down & 0.0208 & 1149 \\
\hline ssc-miR-novel-chrX-41190 & 0 & 431 & 21 & Down & 0.0227 & 335 \\
\hline ssc-miR-novel-chr11-6750 & 7 & 547 & 18 & Down & 0.0305 & 1406 \\
\hline ssc-miR-152 & 332 & 9880 & 21 & Down & 0.0346 & 1161 \\
\hline ssc-miR-542-5p & 0 & 277 & 21 & Down & 0.0348 & 732 \\
\hline ssc-miR-499-5p & 7 & 472 & 21 & Down & 0.0353 & 974 \\
\hline ssc-miR-142-3p & 0 & 238 & 22 & Down & 0.0403 & 887 \\
\hline ssc-miR-135 & 0 & 235 & 23 & Down & 0.0408 & 1602 \\
\hline ssc-miR-194a & 13 & 541 & 21 & Down & 0.0417 & 842 \\
\hline ssc-miR-361-5p & 20 & 704 & 22 & Down & 0.0420 & 867 \\
\hline ssc-miR-185 & 59 & 1621 & 22 & Down & 0.0423 & 2285 \\
\hline ssc-miR-193a-5p & 0 & 201 & 22 & Down & 0.0474 & 1142 \\
\hline ssc-miR-novel-chr5-29676 & 0 & 199 & 23 & Down & 0.0478 & 1066 \\
\hline ssc-miR-183 & 156 & 3132 & 23 & Down & 0.0528 & 1087 \\
\hline
\end{tabular}


Table 2 Top 50 miRNAs significantly up- or downregulated in PK-15 cells in order of fold change (FC) (Continued)

\begin{tabular}{|c|c|c|c|c|c|c|}
\hline ssc-miR-29c & 16 & 366 & 22 & Down & 0.0691 & 1120 \\
\hline ssc-miR-novel-chr5-29857 & 42 & 736 & 19 & Down & 0.0697 & 1711 \\
\hline ssc-miR-29a & 267 & 3939 & 23 & Down & 0.0701 & 1079 \\
\hline ssc-miR-19a & 498 & 6339 & 23 & Down & 0.0800 & 1436 \\
\hline ssc-miR-19b & 1161 & 14,587 & 23 & Down & 0.0802 & 1299 \\
\hline ssc-miR-novel-chr13_10861 & 169 & 1483 & 22 & Down & 0.1199 & 857 \\
\hline ssc-miR-21 & 52,611 & 382,830 & 22 & Down & 0.1374 & 789 \\
\hline
\end{tabular}

Kangcheng Bio-tech inc (Shanghai, China) for Solexa sequencing of miRNAs. The same RNA was used for qRT-PCR.

RT was performed as previously described [6]. Real-time PCR was performed using SYBR Green Real-time qPCR Master Mix (Arraystar, Rockville, MD, USA) on a ViiA 7 Real-Time PCR System (Applied Biosystems, Foster City, CA, USA) according to the manufacturer's instructions. The amplification conditions were as follows: $95{ }^{\circ} \mathrm{C}$ for $10 \mathrm{~min}$, followed by 40 cycles of $95{ }^{\circ} \mathrm{C}$ for $10 \mathrm{~s}$ and $60{ }^{\circ} \mathrm{C}$ for $60 \mathrm{~s}$. Table 1 lists the primers used. All samples were assayed in triplicate. The cycle threshold $(\mathrm{Ct})$ values were analyzed using the $2^{-\Delta \Delta \mathrm{Ct}}$ method. The $U 6$ gene was used as the internal control.

MiRanda and TargetScan were used to predict the targets of the differentially expressed miRNAs. Predicted miRNA targets were functionally annotated through the cell component, biological process, and molecular function information supported by GO analysis. GO analysis and KEGG pathway analyses were performed using DAVID (http://david.abcc.ncifcrf.gov/) with default parameters [7].

\section{Results}

We obtained 3,575,737 and 617,535 high-quality reads from the normal and infected cell samples, respectively, remained for miRNA analysis. The length distribution of the high-quality reads ranged 16-30 nt. Most sequence reads ranged $21-24 \mathrm{nt}$, which belonged to the typical size range (Fig. 1). We identified 533 and 286 porcine miRNAs in normal PK-15 cells and infected PK-15 cells, respectively. This indicates that the normal cells contained more miRNAs than the infected cells. The change of expression of miRNAs between normal and infected PK-15 cells reflects that miRNAs can play key roles during the viral infection process, where virus can affect cellular miRNAs expression profile on their own benefit. ssc-miR-21 was the most abundantly expressed miRNA, followed by sscmiR-30a-5p. miRNAs were considered differentially expressed when the fold change (FC) difference between groups was $>2$ or $\leq 0.5$ and $P \leq 0.01$, or when a miRNA was not expressed in either the infected or control group. There were 193 differentially expressed miRNAs; 128 were downregulated and 65 were upregulated. The most upregulated and downgulated miRNA were ssc-miR-10b (36fold) and ssc-miR-18a (0.01-fold) (Table 2).

We selected 10 miRNAs to confirm the deep sequencing data. The expression levels of ssc-miR-10b, ssc-miR-30a-5p, ssc-miR-16, ssc-miR-17-5p, and ssc-miR-192 in the PPVinfected cells were higher than in the uninfected cells, whereas ssc-miR-21, ssc-miR-19b, ssc-miR-18a, ssc-miR152, and ssc-miR-novel-chr13_10861 were downregulated compared to the uninfected cells (Fig. 2). The results were consistent with that of the deep sequencing analysis. In addition, reverse transcription-quantitative PCR (RTqPCR) indicated the reliability of the deep sequencing data.

In our study, a total 3254 target genes were predicted for the 193 differentially expressed miRNAs. We successfully annotated about 2867 target genes through GO analysis. The upregulated biological process-related genes were involved in cellular process, metabolic process and biological regulation. The biological roles of the downregulated genes were cellular process, metabolic process, and biological regulation. GO enrichment analysis determined functional enrichment of upregulated and downregulated genes in cellular process and cell part and binding (Table 3). The target genes were classified according to Kyoto

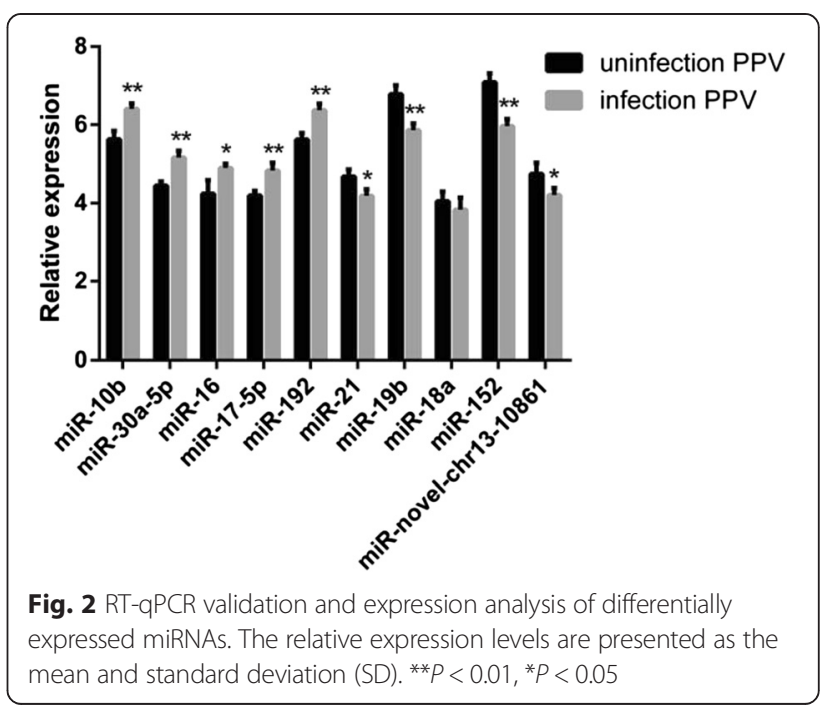


Table $3 \mathrm{GO}$ analysis of swine target genes. The table shows the GO annotation of the upregulated gene (A) and downregulated gene (B) in biological process, cellular component and molecular function. Ten GO terms for each process are listed

\begin{tabular}{|c|c|c|c|}
\hline GO.ID & Term & Count & $P$-value \\
\hline \multicolumn{4}{|c|}{ Biological process } \\
\hline GO:0009987 & cellular process & 1782 & $1.0102 \mathrm{E}-05$ \\
\hline GO:0008152 & metabolic process & 1350 & $2.44953 \mathrm{E}-27$ \\
\hline GO:0065007 & biological regulation & 1260 & 0.000424577 \\
\hline GO:0044238 & primary metabolic process & 1231 & $5.99319 \mathrm{E}-26$ \\
\hline GO:0044237 & cellular metabolic process & 1221 & $1.70495 \mathrm{E}-28$ \\
\hline GO:0050789 & regulation of biological process & 1192 & 0.002408788 \\
\hline GO:0050794 & regulation of cellular process & 1147 & 0.000216533 \\
\hline GO:0002376 & immune system process & 273 & $1.35305 \mathrm{E}-08$ \\
\hline GO:0006955 & immune response & 163 & $1.37682 \mathrm{E}-05$ \\
\hline GO:0000165 & MAPK cascade & 79 & $3.28195 \mathrm{E}-05$ \\
\hline \multicolumn{4}{|c|}{ Cellular Component } \\
\hline GO:0044464 & cell part & 1772 & $1.04304 \mathrm{E}-42$ \\
\hline GO:0005623 & cell & 1772 & $1.25735 \mathrm{E}-42$ \\
\hline GO:0005622 & intracellular & 1589 & $1.48695 E-38$ \\
\hline GO:0044424 & intracellular part & 1512 & $9.75601 \mathrm{E}-38$ \\
\hline GO:0043226 & organelle & 1258 & $3.15768 \mathrm{E}-22$ \\
\hline GO:0043229 & intracellular organelle & 1255 & $5.59497 \mathrm{E}-22$ \\
\hline GO:0005737 & cytoplasm & 1146 & $1.88382 \mathrm{E}-25$ \\
\hline GO:0043227 & membrane-bounded organelle & 1131 & $3.1329 \mathrm{E}-23$ \\
\hline GO:0043231 & intracellular membrane-bounded organelle & 1129 & $3.31685 E-23$ \\
\hline GO:0044444 & cytoplasmic part & 886 & $1.59538 \mathrm{E}-15$ \\
\hline \multicolumn{4}{|c|}{ Molecular Function } \\
\hline GO:0005488 & binding & 1781 & $7.2806 \mathrm{E}-35$ \\
\hline GO:0005515 & protein binding & 1406 & $1.01651 \mathrm{E}-30$ \\
\hline GO:0003824 & catalytic activity & 791 & 4.12422E-11 \\
\hline GO:0043167 & ion binding & 425 & $2.86598 \mathrm{E}-07$ \\
\hline GO:0043169 & cation binding & 423 & 3.71961E-07 \\
\hline GO:0046872 & metal ion binding & 416 & $4.07808 \mathrm{E}-07$ \\
\hline GO:0003676 & nucleic acid binding & 368 & 0.010086661 \\
\hline GO:0036094 & small molecule binding & 366 & 1.33205E-09 \\
\hline GO:0000166 & nucleotide binding & 341 & 4.24208E-09 \\
\hline GO:0097159 & organic cyclic compound binding & 341 & 4.47117E-09 \\
\hline \multicolumn{4}{|l|}{ B } \\
\hline \multicolumn{4}{|c|}{ Biological Process } \\
\hline GO:0009987 & cellular process & 1732 & 0.000468457 \\
\hline GO:0008152 & metabolic process & 1280 & 0.000101041 \\
\hline GO:0065007 & biological regulation & 1226 & 0.039474247 \\
\hline GO:0044238 & primary metabolic process & 1179 & 0.011728824 \\
\hline GO:0044237 & cellular metabolic process & 1153 & 0.011728824 \\
\hline GO:0050789 & regulation of biological process & 1150 & 0.022891558 \\
\hline GO:0050794 & regulation of cellular process & 1100 & 0.023393923 \\
\hline GO:0002376 & immune system process & 265 & $3.49438 \mathrm{E}-08$ \\
\hline
\end{tabular}


Table $3 \mathrm{GO}$ analysis of swine target genes. The table shows the GO annotation of the upregulated gene (A) and downregulated gene (B) in biological process, cellular component and molecular function. Ten GO terms for each process are listed (Continued)

\begin{tabular}{|c|c|c|c|}
\hline GO:0006955 & immune response & 161 & $7.5883 \mathrm{E}-06$ \\
\hline GO:0022402 & cell cycle process & 151 & 0.001985807 \\
\hline \multicolumn{4}{|c|}{ Cellular Component } \\
\hline GO:0044464 & cell part & 1699 & $1.61069 \mathrm{E}-32$ \\
\hline GO:0005623 & cell & 1699 & $1.89406 \mathrm{E}-32$ \\
\hline GO:0005622 & intracellular & 1506 & $1.8551 \mathrm{E}-26$ \\
\hline GO:0044424 & intracellular part & 1426 & $4.89384 \mathrm{E}-25$ \\
\hline GO:0043226 & organelle & 1212 & $8.24637 \mathrm{E}-20$ \\
\hline GO:0043229 & intracellular organelle & 1208 & $2.30659 \mathrm{E}-19$ \\
\hline GO:0043227 & membrane-bounded organelle & 1089 & $8.12018 \mathrm{E}-21$ \\
\hline GO:0043231 & intracellular membrane-bounded organelle & 1088 & $5.50768 \mathrm{E}-21$ \\
\hline GO:0005737 & cytoplasm & 1079 & $5.97213 \mathrm{E}-18$ \\
\hline GO:0044444 & cytoplasmic part & 836 & $2.48602 \mathrm{E}-11$ \\
\hline \multicolumn{4}{|c|}{ Molecular Function } \\
\hline GO:0005488 & binding & 1748 & $3.63499 \mathrm{E}-36$ \\
\hline GO:0005515 & protein binding & 1408 & $1.06202 \mathrm{E}-38$ \\
\hline GO:0003824 & catalytic activity & 743 & $5.00132 \mathrm{E}-07$ \\
\hline GO:0043167 & ion binding & 410 & 2.18765E-06 \\
\hline GO:0043169 & cation binding & 408 & $2.81762 \mathrm{E}-06$ \\
\hline GO:0046872 & metal ion binding & 400 & 4.31756E-06 \\
\hline GO:0003676 & nucleic acid binding & 365 & 0.004482893 \\
\hline GO:0036094 & small molecule binding & 335 & $6.20944 \mathrm{E}-06$ \\
\hline GO:0000166 & nucleotide binding & 309 & $2.81002 \mathrm{E}-05$ \\
\hline GO:0097159 & organic cyclic compound binding & 309 & $2.91504 \mathrm{E}-05$ \\
\hline
\end{tabular}

Encyclopedia of Genes and Genomes (KEGG) function annotations, and we identified pathways actively regulated by the miRNAs during PPV infection (Table 4). Some of the target genes were involved in immunity and virus infection.

\section{Discussion and conclusion}

Previous studies have shown that viruses have evolved a wide variety of means for resisting the host immune system [8-10]. Furthermore, miRNAs play important roles in controlling immune regulation, including cellular differentiation and immune response [11-13]. Identifying and probing miRNAs in the immune system is important for understanding their physiological and pathological roles in PPV infection. In this study, we used high-throughput sequencing to identify miRNAs.

Recent studies have provided compelling evidence that cellular miRNAs play an important role in host defense against virus infection [14]. Many immune-related miRNAs have been identified in innate and adaptive immune systems, including the miR-17-92 cluster, miR-221, miR10, miR-196b, miR-126, miR-155, miR-150; miR-181a, miR-
326, miR-142-3p, miR-424, miR-21, miR-106a, miR-223, miR-146; the let-7 family, miR-9, and miR-34 [6]. We found many differentially expressed miRNAs in the normal and PPV-infected PK-15 cells. Among them, let-7 g, miR-17-5p, miR-17-3p, miR-20a, miR-181a, miR-16, miR-146b, miR$10 \mathrm{~b}$, and miR-155-5p were upregulated; let-7c, miR-122, miR-18a, miR-19a, miR-19b, miR-196b, miR-21, and miR-9 were downregulated. These data suggest that viral mechanisms can affect host miRNA expression. However, we did not detect differential expression of other previously identified miRNAs (miR-223, miR-150, miR-92a), although miR10b, miR-20a, miR-30a-5p, miR-34a, miR-17-5p, miR-16, miR-146b, and miR-155-5p expression was significantly different. In contrast, expression of the downregulated immune-related miRNAs was not significantly different, except miR-18a, miR-19b, and miR-21. This suggests that miRNAs play an important role in the coordinated regulation of immune-related gene expression in PK-15 cells in response to PPV infection.

miR-21, which had high read numbers in both normal and PPV-infected cells, was downregulated; it is related to 
Table. 4 Target genes of 17 differentially expressed miRNAs involved in immune response pathways

\begin{tabular}{|c|c|c|c|}
\hline KEGG pathways & Target genes & Differentially expressed microRNAs & FDR \\
\hline $\begin{array}{l}\text { T cell receptor } \\
\text { signaling } \\
\text { pathway }\end{array}$ & $\begin{array}{l}\text { CTLA4, FYN, IKBKG, NFATC2, NCK1, CD8A, PIK3CG, } \\
\text { CDC42, PTPN6, CD4, CD40LG, ICOS, PIK3R5, } \\
\text { MAPK14, TNF, MAP3K7 }\end{array}$ & $\begin{array}{l}\text { miR-10b, miR-9, miR-30a-5p, miR-17-5p, miR-16, miR-18a, miR- } \\
\text { 19b, miR-20a, miR-19a, miR-122, miR-146b, miR-55-5p, miR-181a, } \\
\text { miR-196b, let-7 g, let-7c }\end{array}$ & $8.89308 \mathrm{E}-12$ \\
\hline $\begin{array}{l}\text { Toll-like } \\
\text { receptor } \\
\text { signaling } \\
\text { pathway }\end{array}$ & $\begin{array}{l}\text { CTSK, TLR7, MAP3K7, MAPK14, CXCL9, PIK3CG, } \\
\text { NFKB1, CD40, STAT1, IL12B, CD86, IL6 }\end{array}$ & $\begin{array}{l}\text { miR-10b, miR-9, miR-30a-5p, miR-17-5p, miR-16, miR-18a, miR- } \\
\text { 19b, miR-20a, miR-21, miR-19a, miR-122, miR-146b, miR-155-5p, } \\
\text { miR-181a, miR-196b, let-7 g, let-7c }\end{array}$ & $1.04578 \mathrm{E}-07$ \\
\hline $\begin{array}{l}\text { NF-kappaB } \\
\text { signaling } \\
\text { pathway }\end{array}$ & $\begin{array}{l}\text { MAP3K7, CXCL12, DDX58, LCK, XIAP, ATM, VCAM1, } \\
\text { NFKB1, TNF, CD40LG }\end{array}$ & $\begin{array}{l}\text { miR-10b, miR-9, miR-30a-5p, miR-17-5p, miR-16, miR-18a, miR- } \\
\text { 19b, miR-20a, miR-19a, miR-122, miR-146b, miR-155-5p, miR-181a, } \\
\text { miR-196b }\end{array}$ & $1.18108 \mathrm{E}-06$ \\
\hline $\begin{array}{l}\text { RIG-I-like } \\
\text { receptor } \\
\text { signaling } \\
\text { pathway }\end{array}$ & $\begin{array}{l}\text { MAP3K7, MAPK14, DHX58, DDX58, IKBKG, TANK, } \\
\text { IKBKB, DDX3X, NFKB1, TNF, IL12B }\end{array}$ & $\begin{array}{l}\text { miR-10b, miR-9, miR-30a-5p, miR-17-5p, miR-16, miR-18a, miR- } \\
\text { 19b, miR-21, miR-19a, miR-122, miR-146b, miR-155-5p, miR-181a, } \\
\text { let-7c }\end{array}$ & 1.70355E-05 \\
\hline $\begin{array}{l}\text { Jak-STAT } \\
\text { signaling } \\
\text { pathway }\end{array}$ & $\begin{array}{l}\text { JAK2, STAT4, STAT5B, JAK3, PIK3CG, PIM1, PTPN6, } \\
\text { TYK2, MAPK14, STAT4, STAT1, IL7R, IL12B, IL6, } \\
\text { PIK3R5, MYC }\end{array}$ & $\begin{array}{l}\text { miR-9, miR-17-5p, miR-16, miR-18a, miR-19b, miR-20a, miR-21, } \\
\text { miR-19a, miR-122, miR-146b, miR-155-5p, miR-181a, miR-196b, } \\
\text { let-7 g, let-7c }\end{array}$ & 0.000124339 \\
\hline $\begin{array}{l}\text { NOD-like } \\
\text { receptor } \\
\text { signaling } \\
\text { pathway }\end{array}$ & MAP3K7, MAPK14, IKBKG, IKBKB, NFKB1, TNF, IL6 & $\begin{array}{l}\text { miR-10b, miR-9, miR-17-5p, miR-16, miR-18a, miR-19b, miR-19a, } \\
\text { miR-122, miR-146b, miR-155-5p, miR-181a, let-7 g, let-7c }\end{array}$ & 0.001546381 \\
\hline
\end{tabular}

immune response and virus replication [15]. Moreover, it is a negative regulator of toll-like receptor 4 (TLR4) signaling by targeting programmed cell death 4 (PDCD4) [16]. miR$19 \mathrm{~b}$ and miR-18a expression was downregulated in the infected cells, suggesting that they play a negative role in PPV replication. Although viruses may downregulate host miRNA by suppressing Dicer expression, the mechanism of downregulation remains unclear [17]. Therefore, future studies are necessary for investigating the mechanism of PPV downregulation of cellular miRNA.

miR-10 expression was upregulated in the infected cells. Mitogen-activated protein kinase kinase kinase 7 (MAP3K7), considered a target gene of miR-10, regulates the inhibitor of nuclear factor $\kappa \mathrm{B} /$ nuclear factor $\kappa \mathrm{B}(\mathrm{I} \kappa \mathrm{B} / \mathrm{NF}-\kappa \mathrm{B})$ signaling pathway [18]. In addition, miR-10 controls brain-derived neurotrophic factor (BDNF) levels via the miRNA-mRNA regulatory network [19]. We surmise that a possible function of miR-10 in triggering an antiviral response is targeting the MAP3K7 and $B D N F$ genes. The miR-30 family is involved in various biological and pathological processes. For example, miR30a may be involved in B cell hyperactivity [20]. We detected miR-10 and miR-30 in this study, suggesting that they are related to the cellular immune response to PPV infection.

GO analysis showed that many of the identified miRNAs found in other studies were predicted to participate in immunity [21]. Many genes, including $M A P 3 K 7$, IRAK1, TLR7, CD40, TGFBR1, RPS6KA3, IGF1R, CDC37, ITGA4, CBLB, ITGA5, IL7, ATM, DPP8, MAPK14, CD2, $W N T 2 B, C A V 1$, and $C D 96$, are involved in the immune- related programs. KEGG analysis showed that these targeted genes could participate in multiple signaling pathways, including that for retinoic acid-inducible gene-I (RIG-I)-like receptor, TLRs, Janus kinase-signal transducer and activator of transcription (JAK-STAT), and Tcell receptor. Interleukin 10 (IL10) plays an important role in virus infection by inhibiting several proinflammatory cytokines [22]. Let-7 g, let-7c, miR-19b, and miR-16 are involved in immune-related programs and may act through the target gene IL10. These results suggest that miRNAs participate in the regulation of piglet immunity. It has been established that miRNAs can target specific genes [23]; in the present study, let-7c, let-7 g, miR-18a, miR-196b, and miR-9 targeted MAP3K7, and miR-196b and miR-19b targeted dipeptidyl-peptidase 8 (DPP8), suggesting that cellular miRNAs play a key role in regulating gene expression in response to PPV infection. Genes targeted by miRNAs are involved in immune response-associated pathways in human parvovirus B19 infection [24]. We speculate that host miRNAs relate to common immune pathways in response to parvovirus infection.

To our knowledge, this is first study to survey the miRNA expression profiles in PPV-infected PK-15 cells through high-throughput sequencing. A number of miRNAs detected were previously described as immune system regulators. Target analysis confirmed that these miRNAs played an important role in PPV infection. These findings contribute to our understanding of the roles miRNAs play in host-pathogen interactions and help with the development of new control strategies to prevent or treat PPV infections in swine. 


\section{Competing interest}

The authors declare that they have no potential conflicts of interest.

\section{Authors' contributions}

Conception and design of the experiments: XQL, LZ, ZWX, YCZ, XGS; Experimental work: XQL; PL; YHC; XGQ; QLL; Data analysis: XQL; YHC; YCZ; manuscript preparation: XQL. All authors read and approved the final manuscript.

\section{Acknowledgments}

This study was supported by the Program for New Century Excellent Talents in University of Ministry of Education of China (Project No: NCET-11-1059), and by the Excellent Doctoral Dissertation Fostering Foundation of Sichuan Agricultural University (04310734). miRNA sequencing services were provided by KangChen Bio-tech, Shanghai, China.

Received: 12 February 2015 Accepted: 14 August 2015

Published online: 20 August 2015

\section{References}

1. Allan G, Kennedy S, McNeilly F, Foster J, Ellis J, Krakowka S, et al. Experimental reproduction of severe wasting disease by co-infection of pigs with porcine circovirus and porcine parvovirus. J Comp Pathol. 1999;121:1-11.

2. Ellis J, Bratanich A, Clark E, Allan G, Meehan B, Haines D, et al. Coinfection by porcine circoviruses and porcine parvovirus in pigs with naturally acquired postweaning multisystemic wasting syndrome. J Vet Diagn Invest. 2000;12:21-7.

3. Opriessnig T, Fenaux M, Yu S, Evans R, Cavanaugh D, Gallup J, et al. Effect of porcine parvovirus vaccination on the development of PMWS in segregated early weaned pigs coinfected with type 2 porcine circovirus and porcine parvovirus. Vet Microbiol. 2004;98:209-20.

4. Sun W, Julie Li Y-S, Huang H-D, Shyy JY, Chien S. microRNA: a master regulator of cellular processes for bioengineering systems. Annu Rev Biomed Eng. 2010;12:1-27.

5. Hicks JA, Yoo D, Liu H-C. Characterization of the microRNAome in Porcine Reproductive and Respiratory Syndrome Virus Infected Macrophages. PLoS One. 2013;8:e82054.

6. Cai Y, Zhu L, Zhou Y, Liu X, Li X, Lang Q, et al. Identification and Analysis of Differentially-Expressed microRNAs in Japanese Encephalitis Virus-Infected PK-15 Cells with Deep Sequencing. Int J Mol Sci. 2015;16:2204-19.

7. Huang DW, Sherman BT, Lempicki RA. Bioinformatics enrichment tools: paths toward the comprehensive functional analysis of large gene lists. Nucleic Acids Res. 2009;37:1-13.

8. Alcami A. Structural basis of the herpesvirus M3-chemokine interaction. Trends Microbiol. 2003;11:191-2.

9. Hiscott J, Kwon H, Génin P. Hostile takeovers: viral appropriation of the NF-kB pathway. J Clin Invest. 2001;107:143-51.

10. Katze MG, He Y, Gale M. Viruses and interferon: a fight for supremacy. Nat Rev Immunol. 2002;2:675-87.

11. Thai T-H, Calado DP, Casola S, Ansel KM, Xiao C, Xue Y, et al. Regulation of the germinal center response by microRNA-155. Science. 2007;316:604-8.

12. Rodriguez A, Vigorito E, Clare S, Warren MV, Couttet P, Soond DR, et al. Requirement of bic/microRNA-155 for normal immune function. Science. 2007;316:608-11.

13. Johnnidis JB, Harris MH, Wheeler RT, Stehling-Sun S, Lam MH, Kirak O, et al Regulation of progenitor cell proliferation and granulocyte function by microRNA-223. Nature. 2008:451:1125-9.

14. Song L, Liu H, Gao S, Jiang W, Huang W. Cellular microRNAs inhibit replication of the $\mathrm{H} 1 \mathrm{~N} 1$ influenza A virus in infected cells. J Viro. 2010;84:8849-60.

15. Lu TX, Hartner J, Lim EJ, Fabry V, Mingler MK, Cole ET, et al. MicroRNA-21 limits in vivo immune response-mediated activation of the IL-12/IFN-gamma pathway, Th1 polarization, and the severity of delayed-type hypersensitivity. J Immunol. 2011;187:3362-73.

16. Coll RC, O'Neill LA. New insights into the regulation of signalling by toll-like receptors and nod-like receptors. J Innate Immun. 2010;2:406-21.

17. Grinberg M, Gilad S, Meiri E, Levy A, Isakov O, Ronen R, et al. Vaccinia virus infection suppresses the cell microRNA machinery. Arch Virol. 2012;157:1719-27.
18. Fang $Y$, Shi C, Manduchi E, Civelek M, Davies PF. MicroRNA-10a regulation of proinflammatory phenotype in athero-susceptible endothelium in vivo and in vitro. Proc Natl Acad Sci. 2010;107:13450-5.

19. Muller S. In silico analysis of regulatory networks underlines the role of miR-10b-5p and its target BDNF in huntington's disease. Translational neurodegeneration. 2014;3:17.

20. Liu Y, Dong J, Mu R, Gao Y, Tan X, Li Y, et al. MicroRNA-30a promotes B cell hyperactivity in patients with systemic lupus erythematosus by direct interaction with Lyn. Arthritis Rheum. 2013;65:1603-11.

21. Zhou Q, Li M, Wang X, Li Q, Wang T, Zhu Q, et al. Immune-related microRNAs are abundant in breast milk exosomes. Int J Biol Sci. 2012;8:118.

22. Sabat R. IL-10 family of cytokines. Cytokine Growth Factor Rev. 2010:21:315-24.

23. Zhou A, Li S, Wu J, Khan FA, Zhang S. Interplay between microRNAs and host pathogen recognition receptors (PRRs) signaling pathways in response to viral infection. Virus Res. 2014;184:1-6.

24. Kühl U, Rohde M, Lassner D, Gross U, Escher F, Schultheiss H-P. miRNA as activity markers in Parvo B19 associated heart disease. Herz. 2012;37:637-43.

\section{Submit your next manuscript to BioMed Central and take full advantage of:}

- Convenient online submission

- Thorough peer review

- No space constraints or color figure charges

- Immediate publication on acceptance

- Inclusion in PubMed, CAS, Scopus and Google Scholar

- Research which is freely available for redistribution

Submit your manuscript at www.biomedcentral.com/submit
C BioMed Central 